\title{
Optimal Electrical Interconnection Configuration of Off-Shore Wind Farms
}

\author{
Mohsen Sedighi, Mohammad Moradzadeh, Osman Kukrer, Murat Fahrioglu, and Lieven Vandevelde
}

\begin{abstract}
Development of large-scale off-shore wind farms (OWFs) around the world has created different technical and economic challenges. Optimal configuration of the electrical interconnection of the OWFs is a key factor to minimize the investment and operational costs. This paper proposes an optimization formulation by using a Genetic Algorithm (GA) to find the optimal electrical interconnection configuration for a given OWF topology with different number of turbines. A search algorithm has been incorporated into the objective function that enumerates all feasible power flow directions from all turbines towards the power collecting hub, identifying the power flow path that minimizes the cable dimensions and thus the overall cost. The algorithm has been tested on several OWF topologies. The impact of the location of the hub has also been investigated by way of simulations. Furthermore, a comparison between single-hub and multi-hub solution has been made for multi-OWF system. The results show that multihub solution can be a better choice in general, especially when only the interconnection cost is compared.
\end{abstract}

Index Terms-Off-shore wind farm (OWF), optimal interconnection configuration, genetic algorithm (GA), transmission line.

\section{INTRODUCTION}

Off-shore Wind Farms (OWFs) are nowadays becoming a preferred solution over on-shore wind farms, to reduce the environmental implications in order to meet the high electrical power demand of modern societies [1]. In general, major difference between the cost of OWF and on-shore ones is the foundations cost, the cost of maintenance and electrical interconnection and transmission system to the shore.

In the past years, some studies aimed to find optimal interconnection configuration by addressing different power collecting systems for on-shore and off-shore wind farms. Reference [2] compares different power collecting methodologies in order to find optimal electrical configuration in on-shore wind farms by considering total cable length with minimum spanning tree algorithm. A similar study has been done in [3] for OWFs. However, they have only considered minimization of the total cable length, and thus a conventional mathematical optimization method

Manuscript received November 4, 2014; revised January 23, 2015.

Mohsen Sedighi and Osman Kukrer are with Dept. of Electrical and Electronic Engineering, Eastern Mediterranean University (EMU), Gazi Magusa, North Cyprus, Mersin 10, Turkey (e-mail: mohsen.sedighi@cc.emu.edu.tr).

Mohammad Moradzadeh and Lieven Vandevelde are with Electrical Energy Laboratory, Dept. of Electrical Energy, Systems and Automation, Ghent University, 9000 Ghent, Belgium.

Murat Fahrioglu is with the Dept. of Electrical and Electronics Engineering, Middle East Technical University-Northern Cyprus Campus, Kalkanli, Güzelyurt, Mersin10, Turkey. is often used. Since the cable dimensions between turbines are not optimized, the optimization result may leads to overdimensioning of the cable system. References [4]-[6] and [1] have worked on optimal interconnection configuration of OWFs by using metaheuristic methods without considering cable dimensions in the optimization problem. Furthermore, the impact of the location of the power collecting hub within the farm is not investigated in most literature.

Some other studies have only investigated the optimal configuration for the transmission system which brings the OWF power to the mainland, without considering the electrical interconnection of the wind turbines within the farm [7], [8].

This paper aims to cover this gap in the literature by optimizing both the interconnecting cable dimensions and the interconnection configuration by using a Genetic Algorithm (GA), as well as illustrating the impact of the location of the hub on the overall cost. Including cable dimension in the fitness function, creates a nonlinear optimization problem (due to existence of a variable cost coefficient), thus GA is an appropriate optimization tool to be used. In this paper, the cable dimensions will be calculated for a given topology of OWF based on the actual current flowing through it. A search algorithm is proposed to identify the optimal electrical configuration associated with the minimum overall cost.

The remainder of the paper is organized as follows: In Section II a brief discussion on the cost of OWFs and Medium Voltage (MV) and High Voltage (HV) cables is provided. Section III discusses the proposed search algorithm and objective function to find the optimal electrical interconnection configuration. In next the section, in part $\mathrm{A}$, the optimal interconnection configuration of three different OWF topologies, each containing 20 turbines, by two different hub locations has been shown. This section is then followed by comparing a single-hub and multi-hub solution for larger OWFs in part B. Finally, Section V summarizes the conclusions.

\section{OFF-SHORE WIND FARMS (OWFS)}

The control concepts and basic technology of wind turbines in both off-shore and on-shore installations are rather the same. Only the turbine size and installation cost are different. For example, acoustic emissions which are important in on-shore wind farm design are not that relevant for the OWF design. Thus, off-shore turbines can be designed for higher speed ratio, hence for the same energy output smaller turbine weight is required. On the other hand, maintenance of the OWFs is time-consuming and more difficult, requiring complex logistical operation shipments 
and mobile gear [9].

Cost is the most significant parameter in the design optimization of the OWFs. The total cost of an OWF can be expressed via the following equation:

$$
C_{\text {tot }}^{O W F}=\left(N \times C_{\text {turb }}\right)+C_{i}+C_{t}+C_{s}^{1}+C_{s}^{2}
$$

where:

$N$ is the number of turbines in OWF,

$C_{\text {turb }}$ total cost of each turbine and the internal transformer (including installation and shipping),

$C_{i}$ total cost of interconnection cables (including laying and shipping),

$C_{s}^{1}$ total cost of off-shore substations (including installation and shipping),

$C_{s}^{2}$ cost of on-shore substation (including installation),

$C_{t}$ total cost of transmission cables (including laying and shipping).

\section{A. Generator and Internal Transformer}

Variable-speed Doubly-Fed Induction Generators (DFIGs) and direct-drive full-scale converter generators are the most widely-used generators for newer wind turbines. In this study, DFIG generators have been considered. Therefore, Power Factor $(\mathrm{PF})$ can be set to unity $(P F=1)$ [10].

In this study, the stator output voltage of the wind turbine generator is considered to be $960 \mathrm{~V}$, thus a step-up $960 \mathrm{~V} /$ $33 \mathrm{kV}$ transformer is used to boost the voltage up to $33 \mathrm{kV}$. The output current of each turbine is calculated as:

$$
I_{L}=\frac{P}{\sqrt{3} \cdot V_{L} \cdot \operatorname{Cos} \varnothing}
$$

\section{B. Cables}

In OWFs it is very important to minimize the cable costs and power losses in the interconnection turbines. Therefore, the required cable dimension between turbines will be calculated according to the actual current in this study.

In order to compare the cost of different interconnection configurations, MV cables with copper conductors (Armored XLPE Insulated) have been considered. The output voltage of the transformer of each turbine is $33 \mathrm{kV}$. The parameters of three-core copper conductors with steel wire armed cable in $33 \mathrm{kV}$ are shown in Table I [11].

\begin{tabular}{|c|c|c|c|c|c|c|c|c|c|}
\hline MV Cable Size $\left(\mathrm{mm}^{2}\right)$ & 50 & 70 & 95 & 120 & 150 & 185 & 240 & 300 & 400 \\
\hline Current (A) & 210 & 255 & 295 & 335 & 375 & 420 & 480 & 530 & 590 \\
\hline $\begin{array}{c}\text { AC resistance at } 90^{\circ \mathrm{C}} \\
(\Omega / \mathrm{Km})\end{array}$ & 0.493 & 0.342 & 0.247 & 0.196 & 0.159 & 0.127 & 0.098 & 0.080 & 0.063 \\
\hline Cost $(€ / m)$ & 85 & 110 & 145 & 180 & 230 & 215 & 270 & 305 & 345 \\
\hline
\end{tabular}

TABLE I: MV CABLE PARAMETERS, 19/33 (36) KV

A $132 \mathrm{kV} \mathrm{HV}$ transmission line will be considered to connect the OWF to the mainland with the parameters of a single core Unarmored XPLE cable given in Table II.

TABLE II: HV CABLES PARAMETERS, 76/132 (145) KV

\begin{tabular}{|c|c|c|c|c|c|c|}
\hline $\begin{array}{c}H V \text { Cable } \\
\text { size }\left(\mathrm{mm}^{2}\right)\end{array}$ & 300 & 400 & 500 & 630 & 800 & 1000 \\
\hline $\begin{array}{c}\text { Current } \\
(\mathrm{A})\end{array}$ & 790 & 882 & 975 & 1066 & 1185 & 1286 \\
\hline $\begin{array}{c}\mathrm{AC} \\
\text { resistance } \\
\text { at } 90^{\mathrm{oC}} \\
(\Omega / \mathrm{Km})\end{array}$ & 0.078 & 0.062 & 0.049 & 0.04 & 0.033 & 0.028 \\
\hline Cost $(€ / \mathrm{m})$ & 350 & 445 & 520 & 635 & 770 & 925 \\
\hline
\end{tabular}

Furthermore, the cost of cable laying operation is considered to be $90 € / \mathrm{m}$ in this study.

\section{OPTIMIZATION PROBLEM FORMULATION}

A GA-based MATLAB code has been developed in this study to identify all feasible paths for power flow from each turbine to the others or to the hub.

\section{A. Search Algorithm}

In this algorithm, illustrated in Fig. 1, the power flow directions which obviously cannot be the optimal have been eliminated to reduce the computational time of the optimization. This becomes very important when the hub is located in the center of the wind farm, as it creates too many possible paths which should be reduced to only feasible ones. Hence, only the paths which can conduct the turbine currents in shortest distance are considered.

The algorithm will take the number of the turbines within the farm ( $n$ turbines in $m$ rows) with the hub location as input, and will output the optimal interconnection configuration such that the total cable cost (considering laying and shipping costs) as well as dimension of cables are optimized. We do this initially by allocating the hub in the center of the farm and dividing the farm into symmetric partitions. In addition, in order to decrease power losses, only $85 \%$ of nominal current has been allowed in each cable.

\section{B. Objective Function}

In order to find the optimal electrical interconnection configuration of OWFs a GA formulation has been used that considers the cable dimension of each branch individually.

The following objective function is proposed to find the optimal electrical configuration that minimizes the total cable cost:

$$
\begin{gathered}
\min C_{\text {cables }}=\sum_{i=1}^{N} \sum_{k=1}^{M_{i}}\left(C_{c(n)}+C_{L, S(i, k)}\right) \cdot L_{(i, k)} \cdot x_{(i, k)} \\
\text { s.t. } \quad \sum_{k=1}^{M_{i}} x_{(i, k)}=1 \quad \forall x_{(i, k)} \in\{0,1\} \\
\quad \sum_{i=1}^{N} \sum_{k=1}^{M_{i}} P_{\operatorname{Loss}(i, k)} \cdot x_{(i, k)} \leq P_{\text {Loss }}^{\max }
\end{gathered}
$$




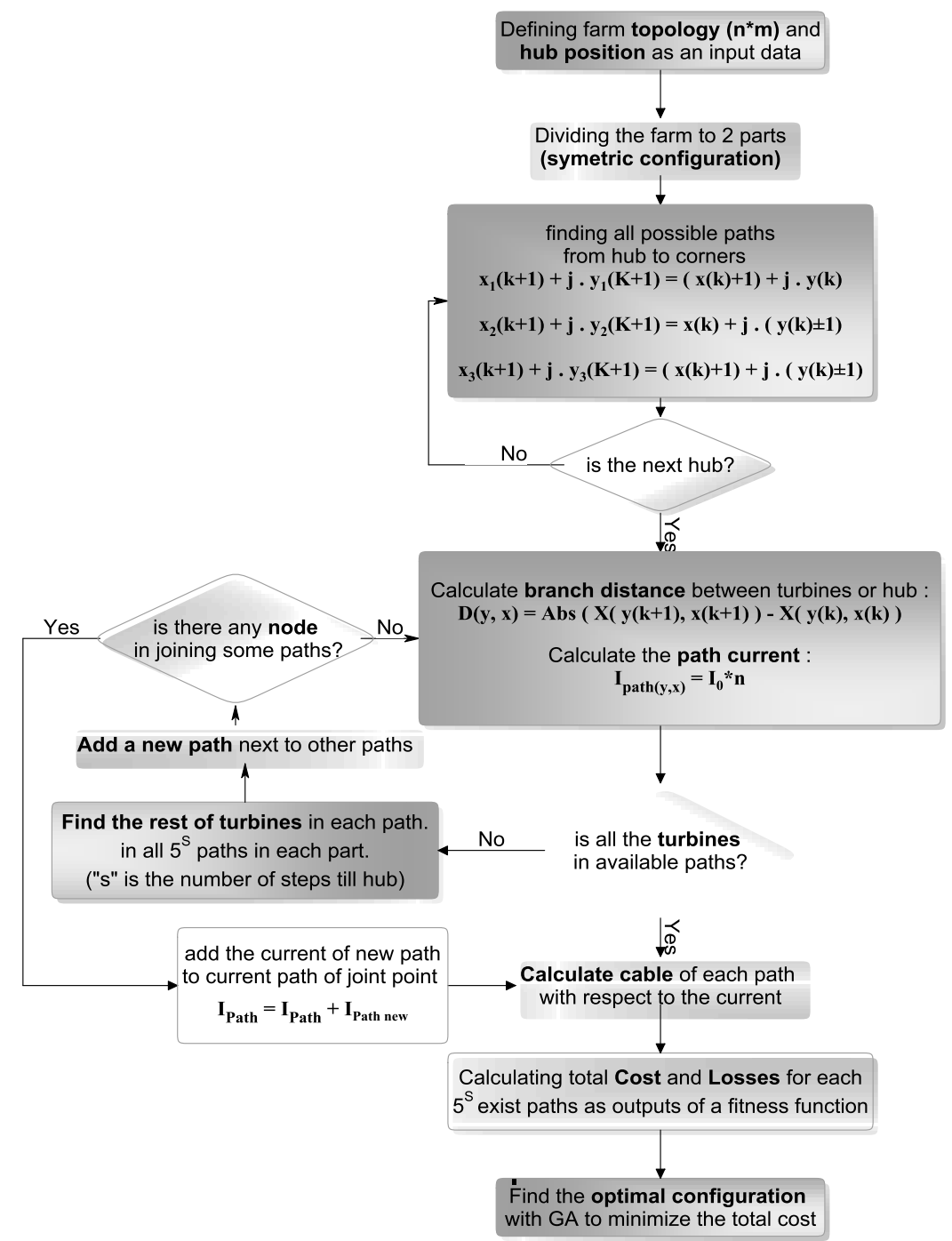

Fig. 1. Flowchart of the search algorithm to find optimal interconnection configuration in each topology.

where:

$N$ is the number of turbines,

$M_{i}$ the number of all feasible branches of $i^{\text {th }}$ turbine,

$x_{(i, k)}$ the $k^{\text {th }}$ feasible branch of $i^{\text {th }}$ turbine,

$L_{(i, k)}$ the length of $k^{\text {th }}$ branch of $i^{\text {th }}$ turbine (m),

$C_{c(n)}$ the cost of calculated cable dimension (n) with respect to the branch current. (Euro/m),

$C_{L, S(i)}$ the laying and shipping cost of cable for $k^{\text {th }}$ branch of $i^{\text {th }}$ turbine (Euro/m),

$P_{\text {Loss }}^{\max }$ the maximum allowed active power losses,

$P_{\text {Loss }(i, k)}$ the active power losses for $i^{\text {th }}$ branch $(\mathrm{kW})$ which can be found from (4).

$$
P_{\text {Loss }(i, k)}=\left(R_{(i, k)} \times I_{(i)}^{2}\right) \times L_{(i, k)}
$$

\section{CASE STUdy}

The minimum admissible distance between turbines must be larger than $4 \times \mathrm{D}$ and larger than $7 \times \mathrm{D}$ between rows, where $\mathrm{D}$ is the diameter of wind turbine blade, and the turbines in the latter row must be located exactly in the middle of the former row according to the rule of thumb [12]. Thus, in this study the distance between turbines in each row and distance between the rows are considered to be $500 \mathrm{~m}$ and $750 \mathrm{~m}$ respectively in all topologies Furthermore, the distance of the hub to the shore is considered to be $50 \mathrm{~km}$ in order to have economic justification for hub connection and using HVAC transmission line. In this study, rated power of all turbines is considered to be $5 \mathrm{MW}$ in all cases.

In section $\mathrm{A}$, a wind farm containing 20 turbines, is considered. In order to find the optimal location for the hub, we will consider two strategic locations for the hub, as shown in Fig. 2.

\section{$5 \times 4$ Farm}

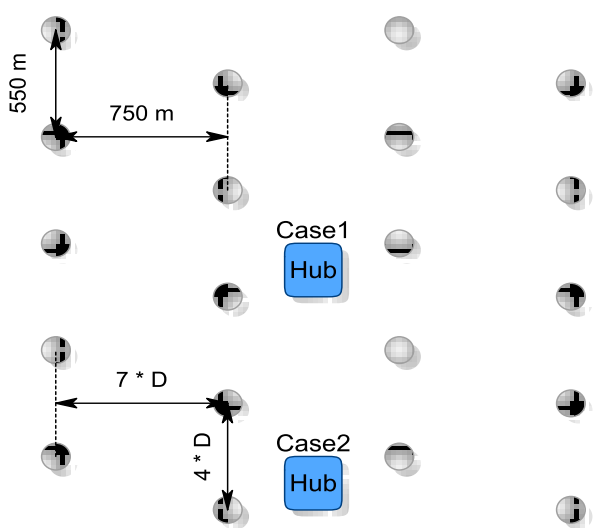

Fig. 2. A sample OWF topology with 20 turbines $(5 \times 4)$. 
In section $\mathrm{B}$, a larger OWF containing 60 turbines will be studied in order to find the optimal interconnection configuration, in single-hub and multi-hub scenarios.

\section{A. Optimal Configuration of Internal Connection}

For an OWF of 20 turbines with the total rated power of $100 \mathrm{MW}$, three different topologies namely $5 \times 4,7 \times 3(7+6+7)$ and $10 \times 2$ will be considered. Furthermore, to study the impact of hub location, two strategic points have been considered for each topology; center of the farm, and outside the farm close to the shore. Therefore, the optimal interconnection configuration minimizing the total cost will be found in two different hub locations of these three topologies.

The comparative results of both hub locations are given in Table III. The topology of $5 \times 4$ has the minimum total cable cost among other topologies in both hub locations. However, the central hub location is economically more viable in terms of investment cost as well as power losses.

TABLE III: TOTAL INTERCONNECTION CABLE COST AND LOSSES OF EACH

\begin{tabular}{|c|c|c|c|c|}
\hline \multicolumn{5}{|c|}{ TopOLOGY IN BOTH Hub LOCATIONS } \\
$\begin{array}{c}\text { Hub } \\
\text { locations }\end{array}$ & Topologies: & $\mathbf{5 \times 4}$ & $\mathbf{7 \times 3}(\mathbf{7 + 6 + 7 )}$ & $\mathbf{1 0 \times \mathbf { 2 }}$ \\
\hline $\begin{array}{c}\text { in center } \\
\text { of OWF }\end{array}$ & $\begin{array}{c}\text { Total Cable Cost } \\
\text { laying and shipping }\end{array}$ & $2.400 \mathrm{M} €$ & $2.468 \mathrm{M} €$ & $2.861 \mathrm{M}$ \\
\cline { 2 - 5 } & Total Losses & $133.5 \mathrm{KW}$ & $138.7 \mathrm{KW}$ & $136.4 \mathrm{KW}$ \\
\hline \hline \multirow{2}{*}{$\begin{array}{c}\text { out of } \\
\text { OWF }\end{array}$} & $\begin{array}{c}\text { Total Cable Cost } \\
\text { laying and shipping }\end{array}$ & $3.159 \mathrm{M} €$ & $3.684 \mathrm{M} €$ & $4.537 \mathrm{M}$ \\
\cline { 2 - 5 } & Total Losses & $146.6 \mathrm{KW}$ & $191.1 \mathrm{KW}$ & $202.6 \mathrm{KW}$ \\
\hline
\end{tabular}

Note that after finding the optimal configuration of each topology, it turns out that the total losses are negligible in comparison with the total power (100MW). Total losses in all topologies are less than $0.14 \%$.

Fig. 3 shows the optimal interconnection configuration for topologies of a) $5 \times 4$, b) $7 \times 3$ and c) $10 \times 2$ OWFs with 20 turbines, where the hub is located to be in the center in order to decrease the overall distance between hub and turbines.

The optimal electrical configurations of these three topologies are also found by locating the hub out of the farm, like most of recent OWFs installations. This hub location only provides an easier access for the maintenance of offshore hub substation. Due to space limitations, only the optimal electrical configuration for topology of $5 \times 4$ has been illustrated in Fig. 4.

Note that, because of larger current flow, some branches require using more than one cable. Therefore, correction factors for such branches have been considered.

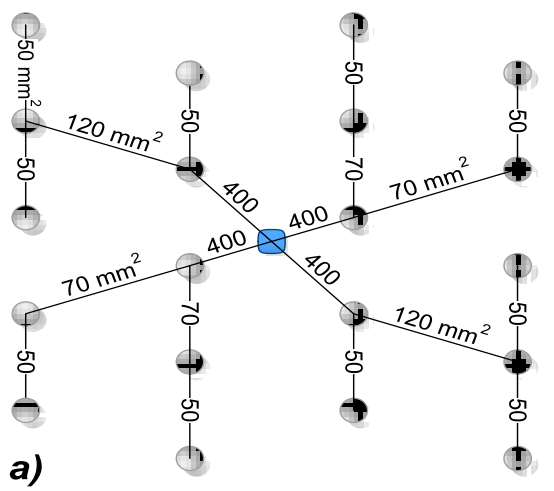

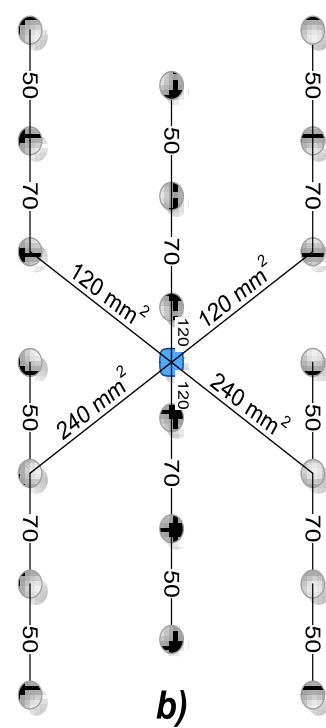

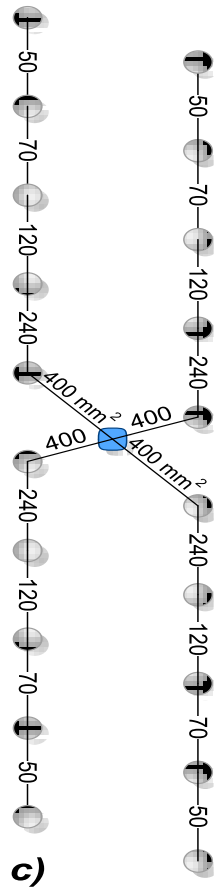

Fig. 3. Optimal configurations of 20 turbines (100MW) for three topologies: a) $5 \times 4$, b) $7 \times 3(7+6+7)$ and c) $10 \times 2$, when the hub located in center.

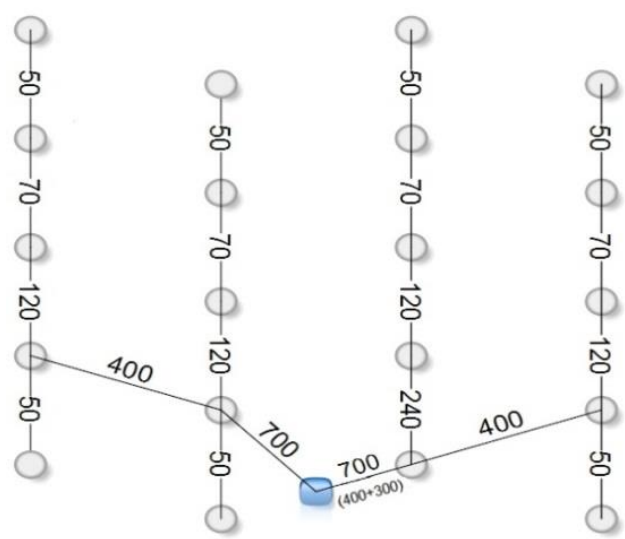

Fig. 4. Optimal configurations of 20 turbines (100MW) with topology of $5 \times 4$, when the hub located out of OWF.

It is also important to mention that, changing the rated power of turbines or the distance between turbines in each row or between the rows may change the optimal interconnection configuration as well as the total cost in each topology. This is not investigated in this paper.

\section{B. Single-Hub and Multi-Hub Solutions in Larger OWFs}

In this section a larger size of OWF with 60 identical turbines and total rated power of $300 \mathrm{MW}$ is considered. The optimal electrical interconnection of the $10 \times 6$ topology in single-hub scenario is shown in Fig. 5.

This single-hub solution is also compared with a multihub solution, as shown in Fig. 6. In both scenarios the same number of turbines (60 turbines) with the identical rated power (5 MW) has been considered.

Scenario I is the optimal interconnection configuration of $10 \times 6$ topology with a single hub and an off-shore transformer. Scenario II divides the $10 \times 6$ topology into three $10 \times 2$ topologies with three hubs and three off-shore transformers. The comparative results of both scenarios are given in Table IV. 


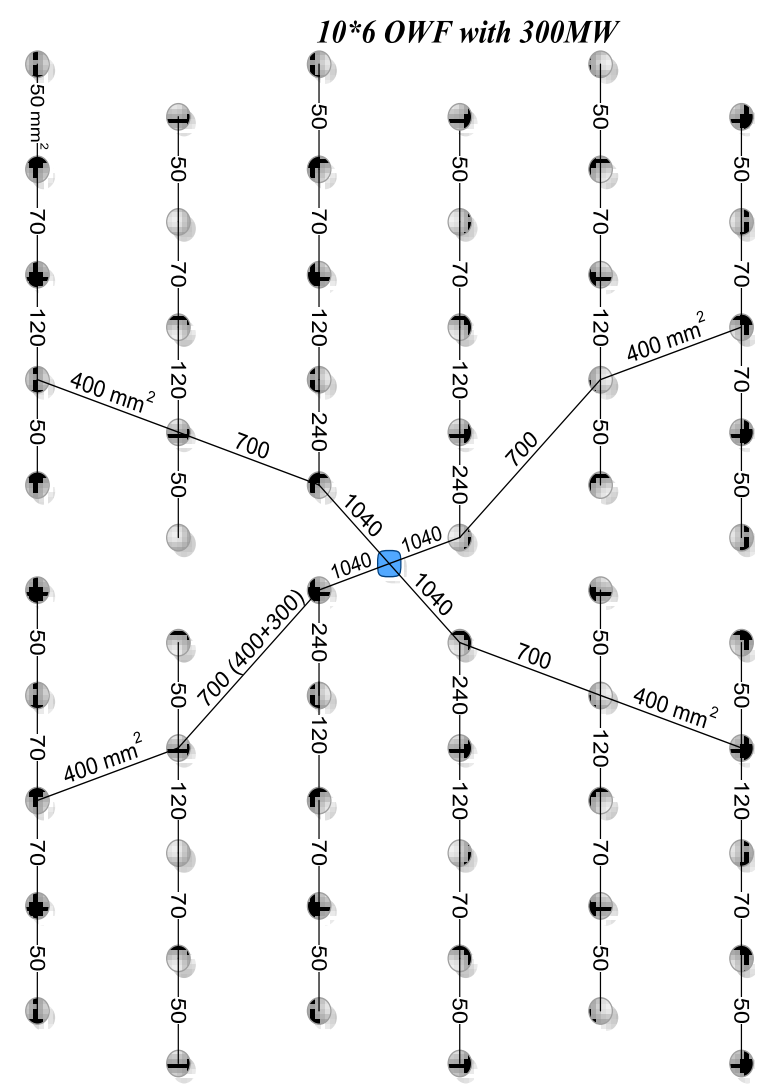

Fig. 5. Optimal configurations of a large OWF with 60 turbines (300MW) with topology of $10 \times 6$ when the hub located in center.

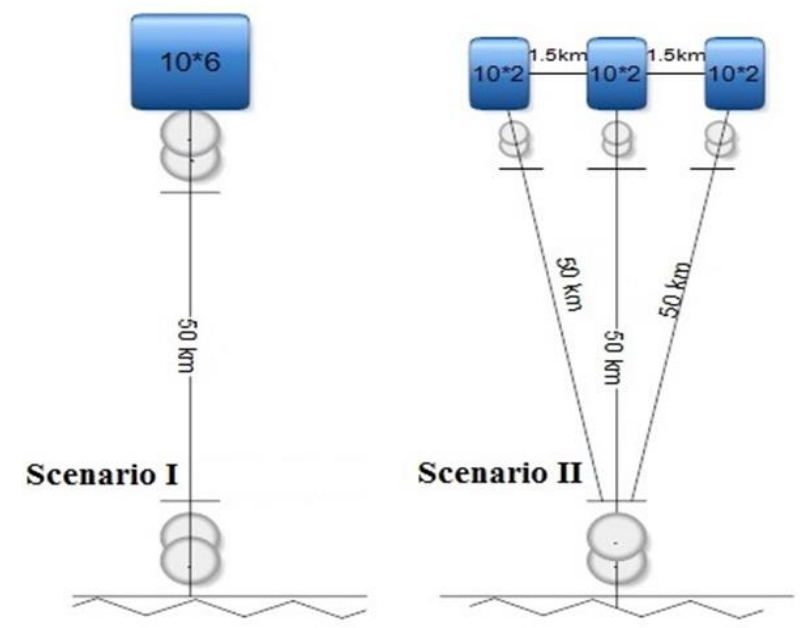

Fig. 6. Comparison between integrated OWF and three individual OWFs scenarios with same power rated and same distance to shore.

TABLE IV: COMPARISON BETWEEN SINGLE-Hub AND MulTi-HuB SOLUTIONS

\begin{tabular}{|c|c|c|}
\hline & $\begin{array}{l}\text { Single-Hub } \\
\text { Farm } 10 \times 6\end{array}$ & $\begin{array}{l}\text { Multi-Hub Farm } \\
3 \times(10 \times 2)\end{array}$ \\
\hline Total Interconnection Losses & $560 \mathrm{~kW}$ & $3 \times 136.4=410 \mathbf{~ k W}$ \\
\hline Total Transmission Losses & $6.6 \mathrm{MW}$ & $3.5 \mathrm{MW}$ \\
\hline $\begin{array}{l}\text { Interconnection Cables Cost } \\
\text { + laying and shipping }\end{array}$ & 13.875 M€ & $\begin{aligned} & 3 \times 2.861 \\
= & \mathbf{8 . 5 8 3} \mathbf{M €}\end{aligned}$ \\
\hline $\begin{array}{l}\text { Off-shore Substation } \\
\qquad(33 / 132 \mathrm{KV})\end{array}$ & $\begin{array}{c}4.785 \mathrm{M} € \\
(400 \mathrm{MVA})\end{array}$ & $\begin{array}{c}6.225 \mathrm{M} € \\
(3 \times 120 \mathrm{MVA})\end{array}$ \\
\hline $\begin{array}{c}\text { Transmission Cable Cost } \\
+ \text { laying and shipping }(50 \mathrm{~km})\end{array}$ & $\begin{array}{c}58.2 \mathrm{M€} \\
\left(2 \times 500 \mathrm{~mm}^{2}\right)\end{array}$ & $\begin{array}{c}64.5 \mathrm{M€} \\
\left(3 \times 300 \mathrm{~mm}^{2}\right)\end{array}$ \\
\hline Total Cost & 78.012 М€ & $78.908 \mathrm{M€}$ \\
\hline Total Losses & 7.16 MW & 3.91 MW \\
\hline
\end{tabular}

The results show that the total cost of the optimal configuration of $10 \times 6$ topology in single-hub solution is slightly lower than the multi-hub solution. However the total losses in multi-hub solution is $55 \%$ of total losses in singlehub solution, and the total cable cost of interconnection itself is about $62 \%$ of this amount in the single-hub solution. Furthermore, after finding the optimal electrical interconnection configuration of OWFs, the overall cost of interconnecting cables and offshore substations turned out to be very small in comparison to the total cable cost of $50 \mathrm{~km}$ transmission line in both scenarios. Thus, multi-hub scenario can be a preferred solution in general, especially when only the total interconnection cost is compared.

\section{CONCLUSION}

The significance of the optimal electrical interconnection configuration in OWFs has been the focal point in different studies. This paper proposes a search algorithm to find the optimal electrical interconnection configuration for a given OWF topology. Moreover, the cable dimension for each path has been included in the cost function to be optimized.

In order to find the optimal configuration of a given OWF topology, all feasible power flow directions have been considered for two different hub locations. The results show that the optimal configurations have minimum cost and losses when the hub is allocated at the center of the farm.

This paper also compares a single-hub solution with a multi-hub solution for a large OWF. The results show that a multi-hub solution can be a preferred choice in general, thanks to its lower total losses and lower total cost of interconnecting cables. However, single-hub solution results in a lower cost in transmission line and off-shore transformers. Furthermore, lower cost of the total interconnection cable in comparison with the total cost of transmission cable illustrates the significant impact of the optimal interconnection configuration of OWF. However, the distance of OWF to the mainland also plays an important role in the overall cost of OWF (this is not investigated in this study).

\section{REFERENCES}

[1] F. M. G. Alez-Longatt, P. Wall, P. Regulski, and V. Terzija, "Optimal electric network design for a large off-shore wind farm based on a modified genetic algorithm approach," IEEE Systems Journal, vol. 6, no. 1, March 2012

[2] S. Dutta and T. J. Overbye, "Optimal wind farm collector system topology design considering total trenching length," IEEE Trans. on Sustainable Energy, vol. 3, pp. 339-348, July 2012.

[3] J. S. Shin, W.-W. Kim, and J. O Kim, "Study on designing for inner grid of offshore wind farm," Journal of Clean Energy Technologies, vol. 3, no. 4, July 2015.

[4] S. Lumbreras and A. Ramos, "Optimal design of the electrical layout of an off-shore wind farm applying decomposition strategies," IEEE Transactions on Power Systems, vol. 28, no. 2, May 2013.

[5] M. Banzo and A. Ramos, "Stochastic optimization model for electric power system planning of off-shore wind farms," IEEE Transactions on Power Systems, vol. 26, no. 3, August 2011.

[6] M. Zhao, Z. Chen, and F. Blaabjerg, "Optimisation of electrical system for off-shore wind farms via genetic algorithm" in IET Renew. Power Generation, vol. 3, iss. 2, pp. 205-216, 2009.

[7] R. E. Torres-Olguin, A. Garces, M. Molinas, and T. Undeland, "Integration of off-shore wind farm using a hybrid HVDC transmission composed by the PWM current-source converter and line-commutated converter," IEEE Transactions on Energy Conversion, vol. 28, no. 1, March 2013. 
[8] H. Ergun, D. Van Hertem, and R. Belmans, "Transmission system topology optimization for large-scale off-shore wind integration," IEEE Transactions on Sustainable Energy, vol. 3, no. 4, October 2012

[9] I. Erlich, F. Shewarega, C. Feltes, F. W. Koch, and J. Fortmann, "Offshore wind power generation technologies," Proceedings of the IEEE, vol. 101, no. 4, April 2013.

[10] X. Du, Y. Zhang, Z. Dai, H. Liu, S. Wei, and J. Liu, "Power distribution strategy considering active power loss for DFIGs wind farm," Journal of Power and Energy Engineering, vol. 2, pp. 213-219, April 2014.

[11] Catalogue of XLPE Insulated Power Cables - universal cable. [Online]. Available: http://www.ucable.com.my/images/products/UC XLPE Catalogue.pdf

[12] M. Samorani, "The wind farm layout optimization problem," Springer Journal, Hand Book of Power System, no. 843, p. 445, 2013.

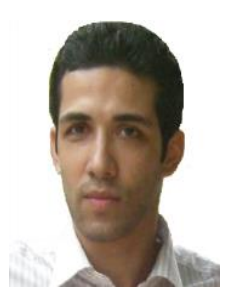

Mohsen Sedighi received the M.Sc. degree in electrical engineering from Semnan University, Semnan, Iran, in 2007. He is currently working toward the Ph.D. degree in Eastern Mediterranean University (EMU), Gazi Magusa, North Cyprus, Turkey. Since 2012, he has been a research assistant with the Department of Electrical and Electronics Engineering, EMU. His research interests are in the field of renewable energy, distributed generation (DG) and optimization techniques applied to complex planning problems in power systems.

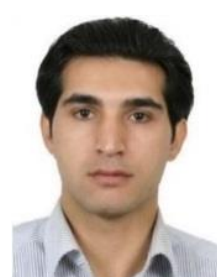

Mohammad Moradzadeh received the M.Sc. degree in electrical engineering from K.N.Toosi University of Technology, Tehran, Iran, and the Ph.D. degree from Ghent University, Belgium, in 2007 and 2012, respectively. He is currently working as a postdoctoral researcher on several industrial projects in Electrica Energy Laboratory (EELAB), Ghent University. His research interests are in the area of renewable energy systems, energy storage and techno-economic operation of smart grids.

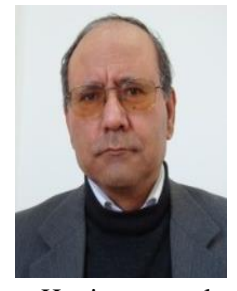

Osman Kukrer received the B.S., M.S., and Ph.D. degrees in electrical engineering from the Middle Eas Technical University (METU), Ankara, Turkey, in 1979, 1982, and 1987, respectively. From 1979 to 1985 , he was a research assistant with the Department of Electrical and Electronics Engineering, METU. From 1985 to 1986, he was with the Department of Electrical and Electronics Engineering, Brunel University, London, U.K

$\mathrm{He}$ is currently a professor with the Department of Electrical and Electronic Engineering, Eastern Mediterranean University, Gazi Magusa, Turkey. He has co-authored more than 50 technical papers in international journals and conferences. His research interests include power electronics, control systems, and signal processing. Dr. Kukrer is a senior member of the IEEE, and a member of the Chamber of Electrical Engineers in North Cyprus.

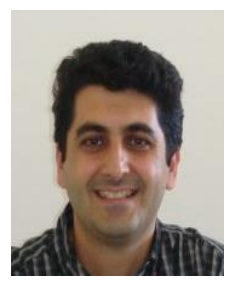

Murat Fahrioglu obtained the BS (Hon) degree in electrical engineering from Michigan State University, in 1993, the MS degree (1994) and the $\mathrm{PhD}$ degree (1999) from the University of Wisconsin - Madison. He is currently an assistant professor at Middle East Technical University - Northern Cyprus Campus in the Department of Electrical and Electronics Engineering. His main interests are in game theory applications in electric power systems and more specifically in the design of demand management contract between electric utilities and their customers to avoid forced outages. He is also working on renewable energy integration into power systems and assessment of solar and wind energy resources.

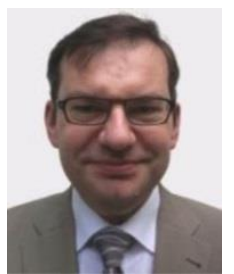

Lieven Vandevelde received the M.Sc. degree in electromechanical engineering and the Ph.D. degree from Ghent University, Belgium, in 1992 and 1997, respectively. $\mathrm{He}$ is with the Electrical Energy Laboratory (EELAB), Ghent University, where he has been a professor in electrical power engineering since 2004. His research and teaching activities are in the field of electric power systems, electrical machines and (computational) electromagnetics. 